12 Kohler G, Milstein C. Continuous cultures of fused secreting antibody of predefined specificity. Nature 1975; 256:495-7.

13 Dolby T, D yton A, Croce CM (in preparation).

14 Shander N, Martinis J, Croce CM. Genetics of human immunoglobulins: assignment of the human chromosome 14. Transplant Proc 1980;12:417-20.

15 McBride W, Leder P (personal communication). Cited by Erickson J, Martinis J, Croce CM. ${ }^{16}$

16 Erickson J, Martinis J, Croce CM. Assignment of the genes for human lambda immunoglobulin chains to chromosome 22. Nature $1981 ; 294: 173-5$.

Requests for reprints to Dr J L García Miranda, Department of Histology, Faculty of Medicine, Ofra, Tenerife, Canary Islands, Spain.

\section{Wildervanck's syndrome with bilateral subluxation of lens and facial paralysis}

SUMMARY A 15-year-old female was found to have the typical features of Wildervanck's syndrome, including Klippel-Feil anomaly, abducens paralysis, retraction of the bulbi, and deafness. In addition, she had bilateral lens subluxation and facial paralysis, neither of which have been reported in patients with Wildervanck's syndrome.

\section{Case report}

The proband was a 15-year-old female, born to a 29-year-old G4, P3, A1 mother, following an uncomplicated term pregnancy with no exposure to agents known to be teratogenic. Delivery was uncomplicated and spontaneous at term. Her birth weight was $3.5 \mathrm{~kg}$. In the first month, the parents noted facial asymmetry. There were no relevant problems until the age of 6 years, when a diagnosis of facial paralysis and fusion of cervical vertebrae was made. The parents were healthy and consanguinity was denied; a younger sister and brother of the patient were normal. There was no family history of any congenital malformation, deafness, or neurological abnormality. Physical examination revealed a well developed girl. She weighed $76 \mathrm{~kg}$ (90th to 95th centile), was $156 \mathrm{~cm}$ tall (10th to 25 th centile), and occipitofrontal circumference was $55 \mathrm{~cm}$ (50th centile). She had facial asymmetry (fig 1), shortness of the neck, pterygium colli, and a low posterior hairline. Neurological examination showed bilateral abducens and right

Received for publication 23 April 1982. facial paralysis, but other neurological alterations, such as hemiplegia, quadriplegia, or paralysis of other cranial nerves, were absent. Ocular examination showed bilateral temporal subluxation of the lens (fig 2) and retractio bulbi. Pupillary size, shape, and reactions were normal, as were the eyelids, corneae, and fundi. An $x$-ray examination showed cervical scoliosis and fusion of the second, third, and fourth cervical vertebrae (fig 3 ). In addition, the patient had bilateral sensorineural deafness. Routine laboratory studies showed normal urine analysis and blood count and blood amino-acid analysis was also normal.

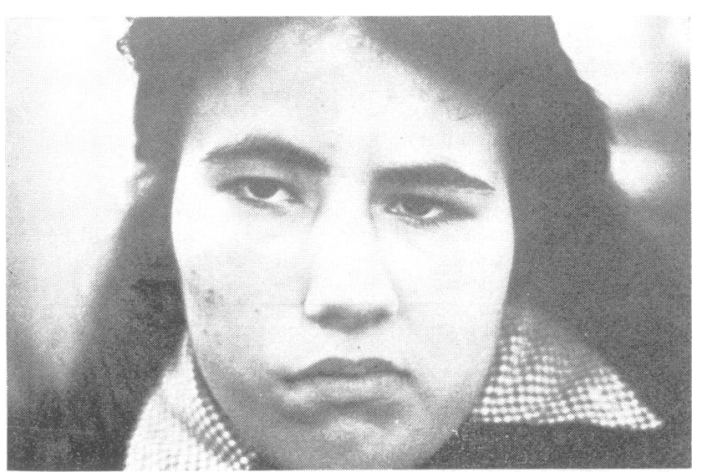

FIG 1 Proband at 15 years of age. Note facial asymmetry.

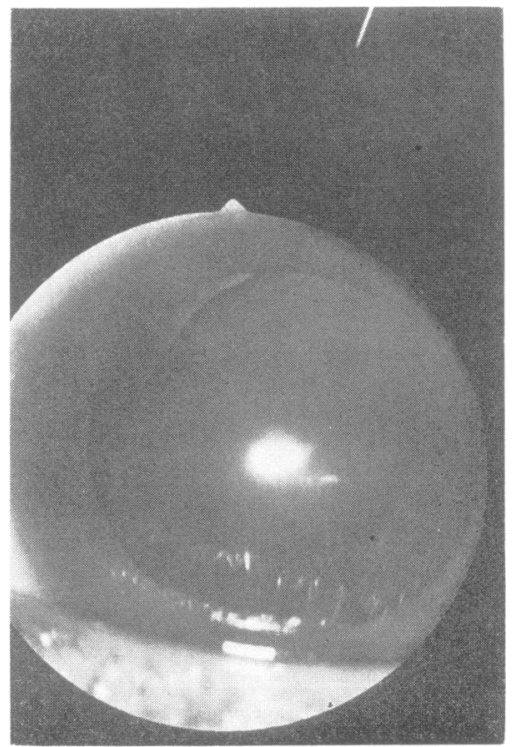

FIG 2 Subluxation of left lens. Similar finding was present in the right eye. 


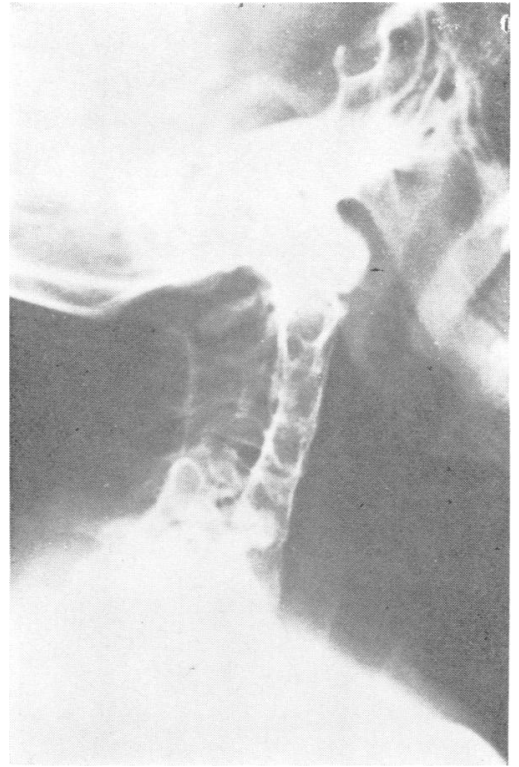

FIG $3 X$-ray film of the cervical spine (lateral view) showing fusion of the second, third, and fourth cervical vertebrae.

\section{Discussion}

A syndrome of Klippel-Feil anomaly, deafness, abducens paralysis, and retraction of the bulbi has been described by Wildervanck ${ }^{1}$ and Wildervanck et al. ${ }^{2}$ Although the syndrome was thought to be responsible for at least $1 \%$ of deafness among girls, ${ }^{3}$ there have been only a few reports of this syndrome in recent years. Moreover, to our knowledge, there are no reports of the association of bilateral subluxation of the lens and unilateral facial paralysis in association with this syndrome. It is possible that the facial paralysis resulted from birth trauma although there was no evidence for this in the history. It is even more difficult to understand lens subluxation in this patient, since we have excluded most metabolic diseases associated with subluxation of the lens, including homocystinuria, sulphite oxidase deficiency, and hyperlysinaemia.

To our knowledge there are no other published reports of developmental syndromes with the clinical features found in our patient. Therefore, either the findings of lens subluxation and facial paralysis are just a coincidence, or they represent previously undescribed associated defects in this rare syndrome. Other reports of this syndrome include other infrequently seen signs, such as pseudopapilloedema ${ }^{4}$ and occipital meningocele, ${ }^{5}$ but not subluxation of the lens and facial paralysis. The syndrome is genetically limited to females which suggests $\mathrm{X}$ linked dominant transmission with lethality in the hemizygous male. Other authors think that multifactorial inheritance is more likely. ${ }^{6}$ Further reports are necessary to establish the incidence of subluxation of the lens and facial paralysis in this syndrome.

We are indebted to Dr Kutay Taysi for the critical reading of the manuscript. This study was supported in part by "Progetto finalizzato Medicina Preventiva", CNR, Rome.

P Strisciuglio,* V Raia,* A Di Meo, $\dagger$
E RinAldi, $\dagger$ AND G ANDRIA*
*Department of Pediatrics, 2nd Faculty of Medicine,
and $\dagger$ Department of Ophthalmology,
1st Faculty of Medicine, University of Naples, Italy.

References

1 Wildervanck LS. Een cervico-oculo-acusticus syndrome. Ned Tijdschr Geneeskd 1960;104:2600-5.

2 Wildervanck LS, Hoecksema P, Penny L. Radiological examination of the inner ear of deaf mutes presenting the cervico-oculo-acusticus syndrome. Acta Otolaryngol $1966 ; 61: 445-53$.

3 McKusick VA. Mendelian inheritance in man. Catalogs of autosomal dominant, autosomal recessive and X-linked phenotypes. 5th ed. Baltimore: Johns Hopkins University Press, 1978:806-7.

4 Kirkham T. Cervico-oculo-acusticus syndrome with pseudopapilloedema. Arch Dis Child 1969;44:504-8.

5 Say B, Balci S, Israel R, et al. Cervico-oculo-acusticus syndrome of Wildervanck. Case report. Turk J Pediatr $1973 ; 15: 157-63$.

6 Konigsmark BW, Gorlin RJ. Genetic and metabolic deafness. Philadelphia: Saunders, 1976:188-91.

Requests for reprints to Dr P Strisciuglio, Department of Pediatrics, 2nd Faculty of Medicine, University of Naples, Via Pansini 5, 80131 Naples, Italy.

\section{$\delta \beta$-thalassaemia in Sicily: report of a case of double heterozygosity for $\mathrm{A}_{\gamma} \delta \beta$-thalassaemia and $\mathrm{A}_{\gamma} \mathrm{G}_{\gamma \delta \beta}$ thalassaemia}

SUMMARY A case of double heterozygosity for $A_{\gamma} \delta \beta$-thalassaemia and $A_{\gamma} G_{\gamma} \delta \beta$-thalassaemia was found during a screening programme in Sicily. The proband, a 4-year-old girl, showed a clinical picture of thalassaemia intermedia. $\mathrm{Hb} \mathrm{F}(85 \cdot 12 \%$ by the Singer method) was $\mathrm{G}_{\gamma} \mathrm{A}_{\gamma}$ type. The parents and the brother were $\delta \beta$-thalassaemia carriers. Structural analysis of $\mathrm{Hb} F$ showed both $\mathrm{G}_{\gamma}$ and $\mathrm{A}_{\gamma}$ chains in the father, but only $A_{\gamma}$ chains in the mother.

Received for publication 19 May 1982. 